\title{
The Latest Edition of the Chapter $X$ in the Seismic Code of Armenia Regarding Seismic Isolation of Buildings and Structures
}

\author{
Mikayel Melkumyan* \\ President of the Armenian Association for Earthquake Engineering, Director of the "Melkumyan Seismic Technologies" \\ LLC
}

\section{*Corresponding Author}

Mikayel Melkumyan

\section{Article History}

Received: 05.01.2021

Accepted: 17.01.2021

Published: 20.01.2021

\begin{abstract}
The National Seismic Code of Armenia was in force since 1994. It contained some provisions regarding the seismic isolation of buildings. However, they were not sufficiently detailed, and this caused barriers for further development of seismic isolation systems in Armenia. Elaboration of a separate chapter dedicated to the seismic isolation of buildings was needed. It was only in 2004 that the works on revision and preparation of the new edition of the National Seismic Code started. This became a good opportunity for addressing the issue again. Moreover, the extensive implementation of seismic isolation technologies especially by the private companies provided a good basis for the inclusion of a separate chapter on seismic isolation of buildings in the mentioned new edition of the Code. The proposal was finally accepted by the RA Ministry of Urban Development and for the first time in the history of development of Seismic Codes in Armenia a Chapter 10 "Seismic isolation of buildings and structures" was included in the Armenian National Seismic Code RABC II-6.02-2006 [1] and was adopted by the Government of Armenia in 2006. The main provisions of this Chapter 10, which consisted of five parts, were described by the author earlier in [2]. Later, when the "Map of Seismic Zonation of the RA Territory" was revised, there was a need to also revise the mentioned Code in force including the Chapter 10. This work started in 2019. The author of this paper is the co-author of the revised Code as a whole. However, together with participating in writing of several parts of the Code he, particularly, prepared the latest edition of the Chapter X named "Buildings and Structures with Base isolation Systems". The works on the revised Code were accomplished in 2020.
\end{abstract}

Keywords: Seismic Code Isolation Buildings and Structures.

\section{Chapter X. Buildings and structures with base isolation systems}

\section{General guidelines}

The guidelines and requirements of the given section cover both the design of the newly constructed buildings and structures of different types, as well as the retrofit of existing buildings and structures with application of Seismic Isolation Laminated Rubber Steel Bearings (hereinafter SILRSBs).

SILRSBs are placed between the foundation and the superstructure (part of the structure above the seismic isolation system) or between the several lower stories and the superstructure (Fig. 9).

Copyright (C) 2021 The Author(s): This is an open-access article distributed under the terms of the Creative Commons Attribution 4.0 International License (CC BY-NC 4.0) which permits unrestricted use, distribution, and reproduction in any medium for non-commercial use provided the original author and source are credited. 


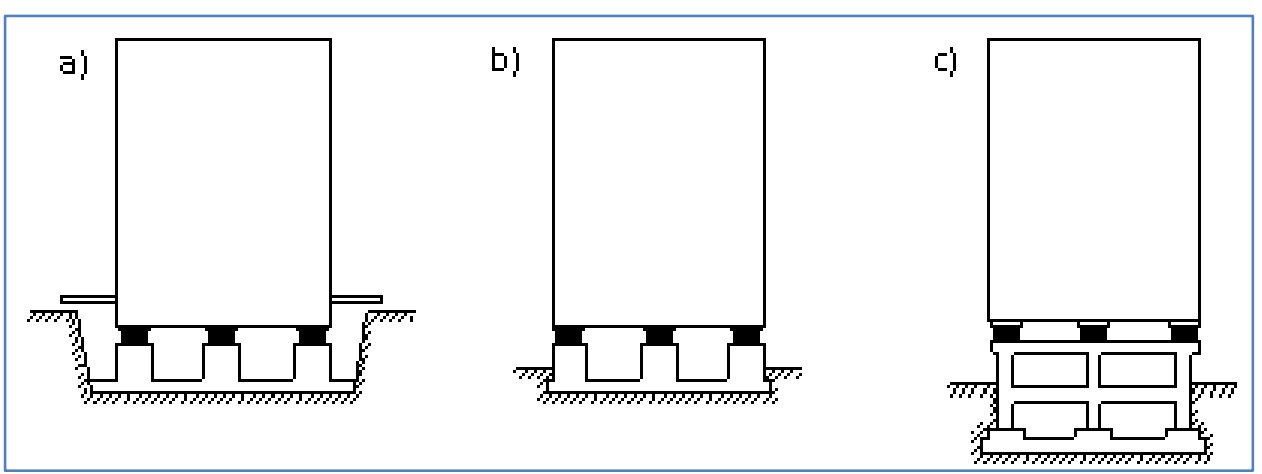

Fig-9: Main types of location of seismic isolation systems

The design of the buildings and structures with seismic isolation systems shall be carried out in accordance with the terms of the technical specifications (TS) and Republican Standards (AST) meeting the requirements of the SILRSBs application. The design shall provide for free access to each SILRSB and possibility, in case of the need, to easily replace them. In the design's "Explanatory note" it is necessary to provide drawings describing the works on possible replacement of seismic isolators. These drawings must include the names of the equipment to be used and the sequence of the works to be carried out. The service lifetime of SILRSBs is warranted individually based on the terms of AST 261 2007 and RABCs specified by the manufacturer.

The seismic isolation is used for buildings and structures with fundamental periods of natural oscillations within 0.05-1.0 sec for regular foundations (i.e., without seismic isolation). Fundamental periods of natural oscillations of seismic isolated buildings and structures must be not more than $3.0 \mathrm{sec}$.

By the structural concepts three types of seismic isolation systems are used: (i) systems located below the level of the pavement around the building (Fig. 9a); and (ii) systems located above the level of the pavement, but no higher than the second story level (Fig. 9b and 9c). In all cases it is necessary to provide by the design sufficient rigidity to the structures below and above the seismic isolation plane. The choice of the seismic isolation type is governed by the soil conditions, functional purpose of a given building, and by the demand of a Customer.

The breaking off force acting upon seismic isolators bolted to the superstructure and foundation shall not exceed values that would cause the tensile stress increase in isolators for more than $1 \mathrm{MPa}$.

The connections of utility lines with the structure shall not increase the seismic isolation system's horizontal rigidity for more than $5 \%$ in case of horizontal movement.

There shall be a seismic gap around the structure, sized at least one and a half times the design displacement for the structure's free horizontal movement on seismic isolators. The preservation of the seismic gap over the service time of the structure shall be ensured by the design solutions on the erection of buildings.

The gap between the lowest part of superstructure and topmost part of the foundation shall be large enough to allow for free vertical static and dynamic deformations of the seismic isolation system for the entire duration of the structure's service time, and when earthquake induced horizontal displacement exceeds the design displacement by one and a half times.

The fire safety rules shall be adhered to in the spaces where seismic isolation systems are housed.

\section{Analysis of Buildings and Structures with Seismic Isolation Systems}

The analysis of buildings and structures with SILRSBs shall be implemented with due regard to the general provisions of the Chapters 4, 5, 6 and 7 of the Code. With the purpose of providing reliability for SILRSBs it is necessary to multiply the values of the design displacements and the vertical gravitation and seismic loads by a factor of 1.1 .

The analysis of buildings and structures with seismic isolation systems is carried out by two methods: (i) according to the provisions of the section 6.4 of the Code, and (ii) by the earthquake response spectra compiled based on recorded accelerograms or synthetic ones generated for the given construction site. The design forces shall be assumed as per the least favorable of the two versions. 
The value of free oscillation period $\mathrm{T}$ for buildings and structures with seismic isolation systems with horizontal stiffness corresponding to the effective stiffness of the seismic isolators is determined by the following formula:

$$
T=2 \pi \sqrt{\frac{Q}{K_{\text {eff }} g}},
$$

Where:

$Q$ - is the aggregate vertical static load (weight of the superstructure) with the combination coefficients factored in as per Table 6 of the Code;

$K_{\text {eff }}$ - is stiffness of the seismic isolation system, which is equal to the sum of effective stiffness of the seismic isolators that comprise the system, as specified by the manufacturer's Technical Specifications (TS) or by the Republic Standards (AST);

$g$ - is the gravitational acceleration.

The design horizontal displacement at the seismic isolation system level, according to (5) of the Code, is determined by the formula:

$$
D=\left(\frac{T}{2 \pi}\right)^{2} A g k_{0} \frac{\beta(T)}{B(\theta)},
$$

Where:

The values of the coefficients $k_{0}$ and $A$ are defined by Tables 4 and 7 of the Code;

Coefficient $\beta(T)$, depending on the soil category, is defined by formulas (7)-(9) of the Code;

The values of the coefficient $B(\theta)$, depending on the value of the critical damping coefficient $\theta$, are given in the Table 1 .

Table-1

\begin{tabular}{|c|c|c|c|c|c|}
\hline $\begin{array}{c}\text { Value of the critical damping } \\
\text { coefficient } \boldsymbol{\theta} \text { in \% }\end{array}$ & $\mathbf{5}$ & $\mathbf{7}$ & $\mathbf{1 0}$ & $\mathbf{1 5}$ & $\mathbf{2 0}$ \\
\hline$B(\theta)^{*}$ & 1 & 1.1 & 1.3 & 1.6 & 1.7 \\
\hline$*$ *) For intermediate values of $\theta$, the values of $B(\theta)$ are defined by linear interpolation \\
\hline
\end{tabular}

If eccentricity exists between the seismic isolation system center of rigidity and the superstructure center of mass, then the value of total design displacement with consideration of seismic isolators' torsion is equal to:

$$
D_{t}=1.1 D
$$

In analysis by accelerograms the horizontal displacements at the level of the top of the seismic isolators shall be determined by the following formula:

Where:

$$
\begin{gathered}
D=\left(\frac{T}{2 \pi}\right)^{2} \tau_{\max }(T, \theta), \\
\tau(T, \theta)=\frac{2 \pi}{T} \int_{0}^{t} e^{-\phi(t-\xi)} y_{0}^{*}(\xi) \sin \frac{2 \pi}{T}(t-\xi) d \xi,
\end{gathered}
$$

$\tau_{\max }(T, \theta)$ - is the seismic response spectrum ordinate at $T=T_{\text {eff }}$ according to the actual or synthetic accelerogram $y_{0}{ }_{0}(t)$ selected for the given construction site. At calculation of $\tau(T, \theta)$ the value of the critical damping coefficient is assumed equal to the actual value of $\theta$ obtained during the SILRSBs tests.

The total design displacement $D_{t}$ must be less than that of the seismic isolators, which corresponds to their effective stiffness $K_{\text {eff }}$ during the cyclic tests carried out in accordance with the manufacturer's Technical Specifications.

\section{Horizontal Seismic Transvers Force}

The value of horizontal seismic transfer force generated during an earthquake on the top of the isolators (at the base of superstructure) is determined by the following formula:

$$
S=K_{\mathrm{eff}} \cdot D_{\mathrm{t}}
$$


For analysis by accelerograms the value of $D_{t}$ is assumed equal to $D$ as per formula (34).

The strength analysis of elements connecting seismic isolators to the superstructure, as well as those to the foundation is performed under action of the horizontal force (35).

The design value of the horizontal seismic load $S_{k}$ applied at the point k of the superstructure with weight $Q_{k}$ is determined by the following formula:

$$
S_{k}=\frac{S k_{1} Q_{k} h_{k}}{\sum_{i=1}^{n} Q_{i} h_{i}}
$$

Where:

$h_{k}$ - is the height from the base of superstructure to the concentrated load $Q_{k}$. The values of the permissible damage coefficient $k_{l}$ and the story drifts $\Delta_{k}$ for the superstructures of various structural concepts are taken from Table 8 of the Code.

\section{Design Models of Seismic Isolation Systems}

In analysis by accelerograms the seismic isolation systems can be modeled in linear or non-linear "forcedisplacement" relationship. For the linear seismic isolation system, the structure is considered as a rigid body and the higher modes of vibrations are not considered. For the non-linear seismic isolation system, the influence of higher modes shall be duly regarded.

\section{The linear model of seismic isolation is applied when}

- the structural system of a building or structure is homogeneous;

- the period of the structure's natural oscillations without seismic isolation is $\leq 0.6 \mathrm{sec}$;

- the relative eccentricity between the structure's center of mass and the seismic isolation system's center of rigidity does not exceed 0.01 ;

- $\quad$ isolators are placed in a single plane;

- the vertical stiffness of the isolator is at least 200 times more than its horizontal stiffness.

Non-linear seismic isolation system is considered into the model in cases not specified above for the linear model as well as when applying SILRSBs with damping characteristics of $10 \%$ and more.

With a structural concept for the superstructure in plan and along the height, meeting the requirements of the Chapter VII of the Code, the superstructure should be modeled in the form of a vertical rod, resting upon the seismic isolation system, which is rigidly connected to the soil (base), and having the masses concentrated on the levels of the slabs. At the same time, the rods between the masses are weightless, and their horizontal stiffness is equal to the sum of horizontal stiffnesses of all the vertical bearing elements on the given story level.

\section{Design of the Superstructure and Seismic Isolation Systems}

Footings under seismic isolators can be of strip and spread types. Spread footings shall be connected to each other with rigid ties.

A horizontal frame bound with a rigid disc of the floor slab shall be arranged on the top of the seismic isolators. Its design model represents a continuous system resting on concentrated elastic supports. The frame shall be rigidly tied to the superstructure and have a design solution that prevents torques in its structural elements.

The superstructure of the seismically isolated buildings and structures (except stone buildings) shall be designed for the First Seismic Zone in accordance with structural requirements set forth in the Chapter VII of the Code.

The seismic isolators in plan are placed with consideration of the building configuration and uniform distribution of vertical loads on them. The distances between seismic isolators or groups of seismic isolators shall not differ from each other by more than 1.5 times.

The system of utility lines in the buildings with seismic isolation shall have flexible connections and compensators that allow damage-free shift of utility lines elements for the value of the design displacement determined by the formula (33). 
The configuration of buildings and structures with seismic isolation systems shall be as simple as possible both in plan and along the height. Up to 12-storey buildings and structures may have height level differences of no more than the size of three stories (no more than 11 meters), as well as asymmetric geometric shapes in plan.

To minimize the eccentricity between the center of horizontal rigidity of the seismic isolation system and the structure's center of mass projection on the SILRSBs plane, the scatter of vertical loads on seismic isolators of the same stiffness shall not exceed $\pm 20 \%$. It is allowed to use two or more SILRSBs under the bearing structures of the superstructure. In seismic isolation systems SILRSBs must be placed by clusters using the same type of seismic isolators so that the torsion of the superstructure is neutralized.

\section{REFERENCES}

1. Republic of Armenia Ministry of Urban Development. (2006). Earthquake Resistant Construction Design Code RABC II-6.02-2006. - Yerevan.

2. Melkumyan, M. (2011). Chapter 13. Development of the code for design of seismic isolated buildings and comparison of the results of analyses based on the code and time histories. - In the book "New Solutions in Seismic Isolation", Yerevan, "LUSABATS". 219-226.

CITATION: Mikayel Melkumyan (2021). The Latest Edition of the Chapter X in the Seismic Code of Armenia Regarding Seismic Isolation of Buildings and Structures. South Asian Res J Eng Tech, 3(1): 8-12. 